\title{
Regulação do vídeo sob demanda na américa do sul: Um olhar para o estado da arte
}

Regulation of video on demand in south America: a look at the state of the art

Regulación de vídeo bajo demanda en America del sur: un vistazo para el estado del arte

\section{Luiz Gustavo SANTANA CAMPOS \\ Universidade Federal da Bahia - Brasil \\ lugsca@gmail.com}

\section{Daniele PEREIRA CANEDO}

Universidade Federal do Recôncavo da Bahia - Brasil danielecanedo@ufrb.edu.br

Chasqui. Revista Latinoamericana de Comunicación

N. ${ }^{\circ}$ 147, agosto-noviembre 2021 (Sección Diálogo de Saberes, pp. 313-330)

ISSN 1390-1079 / e-ISSN 1390-924X

Ecuador: CIESPAL

Recibido: 06-04-2021 / Aprobado: 10-07-2021 


\title{
Resumo
}

Os últimos anos foram marcados pelo surgimento dos serviços de vídeo sob demanda como novas tecnologias atuantes em todos os setores da cadeia produtiva do audiovisual. A regulação se coloca como um dos principais pontos da agenda, amplamente discutida por pesquisadores da área. Este artigo apresenta uma revisão de literatura, a partir da construção e análise de um portfólio bibliográfico focado na temática da regulação para os serviços de vídeo sob demanda na Argentina, Brasil e Colômbia, entre 2009 e 2019. Os resultados indicam quatro principais temas que aparecem de forma transversal e recorrentemente entre as produções científicas analisadas.

Palavras-chave: regulamentação; streaming; vídeo sob demanda; diversidade cultural

\begin{abstract}
The last few years have been marked by the emergence of video-on-demand services as new technologies in all sectors of the audiovisual production chain. The regulation is one of the main points on the agenda being widely discussed by researchers in the area. This article presents a literature review, from the construction and analysis of a database focused on the theme of regulation for video-on-demand services in Argentina, Brazil and Colombia, between 20092019. The results indicate four main themes that appear transversally and repeatedly among the scientific productions analyzed.
\end{abstract}

Keywords: regulation; streaming; video on demand; cultural diversity

\section{Resumen}

Los últimos años han estado marcados por el surgimiento de los servicios de vídeo bajo demanda como nuevas tecnologías en todos los sectores de la cadena de producción audiovisual. La regulación es uno de los puntos principales del orden del día, siendo ampliamente discutido por los investigadores de la zona. Este artículo presenta una revisión bibliográfica, a partir de la construcción y análisis de una base de datos centrada en el tema de la regulación de los servicios de video bajo demanda en Argentina, Brasil y Colombia entre 2009-2019. Los resultados indican cuatro temas principales que aparecen transversalmente y recurrentemente entre las producciones científicas analizadas.

Palabras clave: regulación; streaming; vídeo bajo demanda; diversidad cultural 


\section{Introdução}

Nos últimos anos, a sociedade se deparou com uma nova forma de acesso a conteúdos audiovisuais que tem ganhado cada vez mais espaço em todas as etapas da cadeia produtiva do setor audiovisual. Os serviços Over the Top (OTT) agrupam modelos que utilizam a internet para a transmissão de dados para um dispositivo online (Andrade, Toledo, \& Corrêa, 2013). Entre os modelos, está a comunicação audiovisual sob demanda (video on demand ou VOD, na sigla em inglês), difundida a partir da popularização dos aparelhos portáteis e do avanço das tecnologias de compartilhamento de dados pela internet ${ }^{1}$.

A ampliação do consumo de vídeo a partir de mídias digitais tem registrado crescimento vertiginoso nos últimos anos. Estudos estimam que em 2022, 60\% da população mundial estará conectada à internet e os vídeos serão responsáveis por $82 \%$ do tráfego de dados (Cisco, 2018). Projeções como essa, alinhadas ao sucesso de empresas como Netflix e YouTube, são consonantes à migração parcial, e até mesmo total, dos consumidores e das empresas dos modelos de negócios tradicionais do audiovisual para o VOD.

O estabelecimento dos serviços OTTs logo suscitou o debate sobre regulação para esses serviços. Trata-se de uma pauta já presente nas discussões do setor audiovisual, que se baseia em normativas anteriores do cinema, da televisão aberta e da televisão por assinatura. São debates presentes em vários países do mundo, ainda que em distinta situação de amadurecimento, sendo essa uma diferença evidente quando comparamos o contexto europeu com o latino-americano, por exemplo. Países como França, Alemanha e Bélgica desenvolveram normativas voltadas especificamente para os serviços de VOD, uma vez que foram identificadas brechas na regulamentação já existente para o cinema e o audiovisual (Donders et al, 2018). No centro da discussão em solo europeu está o entendimento do audiovisual como expressão cultural, assim como a percepção de uma indústria a ser incentivada e protegida, sobretudo, do desenfreado monopólio estadunidense representado pelas maiores empresas do setor (Canedo, 2013).

Na América Latina, ainda que a passos mais lentos, países como Argentina, Brasil e Colômbia discutem regulações baseadas em legislações anteriores já consolidadas, como a Lei do Audiovisual e a Lei da TV Paga, no Brasil. Por outro lado, tal discussão também tem fomentado a revisão das normativas para os modelos tradicionais, uma vez que as operadoras questionam estarem em situação de desigualdade em relação ao VOD.

1 A popularização do termo "streaming", ou ainda "plataforma de streaming", como referências a este novo modelo de plataforma, pode causar confusões quando, no diálogo, são inseridos termos como OTTs, VOD e tantos outros. Ainda que na linguagem informal todos possam se referir aos serviços oferecidos por empresas como Netflix, Amazon Prime, Hulu e GloboPlay, o termo "streaming" refere-se à tecnologia utilizada para o compartilhamento de dados e arquivos em geral. Dessa forma, neste artigo trabalharemos com o termo vídeo sob demanda (VOD) no intuito de deixar marcado o foco no setor audiovisual. 
A relevância da pauta na agenda pública tem reverberado no expressivo aumento da produção acadêmica sobre VOD, em todas as suas temáticas e enfoques, estando a regulamentação inclusa nesse escopo. As investigações giram em torno das potencialidades e entraves que as regulamentações para os serviços VOD podem trazer para a organização da sociedade, o desenvolvimento da indústria audiovisual e a promoção da diversidade cultural.

Com o objetivo de compreender o estado da arte da produção acadêmica na área, identificando as principais abordagens e características, este artigo apresenta uma revisão de literatura sobre a regulação do vídeo sob demanda na Argentina, Brasil e Colômbia, no período de 2009 a 2019. O artigo está dividido em três partes, além desta introdução e da conclusão. A primeira apresenta o marco teórico. Em seguida, descreve-se as escolhas metodológicas feitas no processo e na composição do Portfólio Bibliográfico. Por último, são apresentadas as discussões e os resultados, indicando quatro principais temas que aparecem recorrentemente entre as produções científicas analisadas: a) regulação para novas tecnologias; b) entraves e potencialidades das regulamentações; c) diferenças entre a construção regulatória na Europa e na América Latina; e d) relação entre a regulamentação para o VOD e mercado e normativas para a TV Paga.

\section{Marco teórico}

O debate sobre a regulação de conteúdos audiovisuais sob demanda está intimamente ligado a uma agenda anterior ao seu próprio surgimento, relacionando-se à construção regulatória dos serviços tradicionais do audiovisual como o cinema e a televisão por assinatura. Contudo, está conectado, principalmente, a bases teóricas que ressaltam as interdependentes dimensões cultural, econômica, tecnológica e política do setor audiovisual.

Para além dos aspectos artístico e identitários, centrais para as produções audiovisuais, o setor leva consigo um importante aspecto econômico. Através da troca de bens simbólicos, o audiovisual contribui para a geração de emprego e renda de milhões de trabalhadores, movimentando a economia de países e regiões. Um relatório da Ancine publicado em 2020, com dados de 2015 a 2018, aponta que o audiovisual é o quinto setor da indústria brasileira com o maior valor agregado, registrando $\mathrm{R} \$ 26,7$ bilhões e superando as indústrias farmacêutica e têxtil (Ancine, 2020).

Diversos autores datradição de estudos daEconomia Política da Comunicação (EPC) analisam a produção cultural a partir de especificidades econômicas e políticas, ressaltando a importância de incluir nos estudos as relações de poder, a estratificação social e as condições de produção, distribuição e intercâmbio da produção cultural (Garnham, 1979; Golding, Murdock, 1981; Bolaño et al, 2009). Kátia Moraes et al (2017), defendem a utilidade da relação entre política e economia proposta pela EPC para analisar a atuação dos agentes do setor 
audiovisual nos distintos momentos da cadeia produtiva. Ademais, ressaltam que a dinâmica entre os agentes econômicos, o Estado e suas instituições é o fator central para as condições de competitividade no mercado audiovisual internacional (Moraes et al, 2017). Dinâmica essa na qual o debate sobre marcos regulatórios torna-se indispensável.

A Economia Política da Comunicação também defende a dimensão moral da análise e o papel da pesquisa acadêmica sobre cultura como promotora de valores sociais como a democracia, a igualdade de direitos e o predomínio dos interesses da esfera pública em oposição aos interesses privados (Mosco, 1996). Entretanto, historicamente, os indicadores da cadeia produtiva do audiovisual sugerem tratar-se de um setor marcado pelas desigualdades e pelo controle do poder econômico e político por poucos grupos empresariais (Canedo, 2013). A adoção, em 2005, da Convenção sobre a Proteção e Promoção da Diversidade das Expressões Culturais (UNESCO, 2006), foi um marco histórico de uma longa negociação sobre a liberalização do comércio internacional de produtos audiovisuais que começou em 1947. No cerne das discussões estavam dois grupos com posicionamentos opostos.

O grupo de países liderado pelos Estados Unidos defendia que o audiovisual deveria ser tratado pela Organização Mundial do Comércio (OMC) como qualquer outro produto comercial. Assim, o setor estaria submetido a regras de liberalização do comércio internacional que limitariam regulamentações e políticas nacionais de incentivo à produção, cotas de tela, cooperação regional, entre outras medidas. Já o grupo liderado pela França e pelo Brasil defendia a exceção cultural, acentuando o caráter específico da dualidade simbólica e econômica do audiovisual. O grupo defendia o direito dos países de desenvolverem normativas e políticas públicas, de modo a promover a produção nacional e limitar o controle hegemônico do mercado audiovisual. A ratificação da convenção por mais de 140 países sinalizou a importância de políticas e regulamentações como instrumentos garantidores de um adequado ambiente para a consolidação do exercício dos direitos culturais.

O debate sobre regulação, de outra forma, está inserido também a partir de um entendimento da cultura não somente como meio, mas também como fim das políticas para o desenvolvimento. Tal debate encontra forte reverberação nos escritos de autores como Celso Furtado (1961) e Amartya Sen (2000) que entendem o desenvolvimento de forma ampla, como capacitador das ações dos sujeitos e do aprimoramento das relações e condições sociais.

São reflexões que dão um passo além e percebem a cultura como elemento do sistema de relações políticas, econômicas e sociais entre os Estados centrais e periféricos do sistema internacional. Os escritos de Furtado (1961) sobre desenvolvimento na América Latina, por exemplo, se destacam por defender o fortalecimento da indústria nacional - onde o audiovisual certamente se encaixaria - atrelado ao debate sobre mimetismo cultural e desenvolvimento endógeno. Na visão do autor, a consolidação de uma identidade cultural 
própria da periferia se caracteriza como elemento central para que inovações tecnológicas e políticas se deem a partir de especificidades e potencialidades do local (Rodrigues, 2009).

Inegavelmente, muitos dos entraves do setor audiovisual de países periféricos possuem íntima relação com fragilidades econômicas e políticas, resultantes da exploração colonial e de processos monopolistas por quais tais países passaram ao longo dos anos, e, mais recentemente, da dependência tecnológica. As vulnerabilidades das indústrias nacionais responsáveis pela produção de maquinário essencial para a produção audiovisual, incidem diretamente na necessidade de importação de equipamentos e tecnologias necessárias para o estabelecimento de uma cadeia produtiva consolidada. Assim, o cenário de dependência visualizado em outros setores econômicos da sociedade, que possuem forte amparo na indústria, é também identificado no setor audiovisual.

Néstor García Canclini (1995) entende essa situação como uma importante contradição a ser demarcada, uma vez que o contexto da produção ou distribuição não se repete quando pensamos no consumo de produtos audiovisuais. Para o autor, que em "Consumidores e Cidadãos" direciona seu olhar para a América Latina, os países da região são desenvolvidos no consumo, mas ainda em desenvolvimento nas outras etapas da cadeia produtiva do setor. Não por acaso, países como Argentina, Brasil e México são entendidos como grandes consumidores de produções audiovisuais e vistos como importantes mercados para os grandes conglomerados. Por outro lado, continuam enfrentando dificuldades para comercializar e exibir produções audiovisuais nos grandes mercados internacionais -e muitas vezes nos próprios mercados nacionais- tendo em vista a concorrência com produções advindas de indústrias já consolidadas.

\section{Metodologia}

A revisão de literatura é embasada na metodologia ProKnow-C (Knowledge Development Process - Constructivist), desenvolvida pelo Laboratório de Metodologias Multicritério em Apoio a Decisão (LabMCDA), da Universidade Federal de Santa Catarina (Ensslin, Ensslin, Lacerda, \& Tasca, 2010). A metodologia prevê uma sequência de procedimentos que inclui a definição dos mecanismos de busca a serem utilizados; a filtragem e seleção do portfólio bibliográfico sobre o tema; a leitura e a análise dos trabalhos identificados. A seguir descreve-se a aplicação da metodologia, expondo as decisões tomadas para a construção de um portfólio bibliográfico sobre a regulação dos serviços de vídeo sob demanda.

A primeira etapa do processo prevê a definição de um conjunto de palavraschave relacionadas desde o universo mais amplo do escopo da pesquisa até o mais específico. $\mathrm{O}$ termo video on demand foi escolhido pela permeabilidade nos 
mecanismos de busca, mesmo no processo de busca de artigos em português e espanhol. No grupo intermediário constam os três países focos da pesquisa. As variações dos termos regulamentação e regulação, tanto para o português, quanto para o espanhol, foram escolhidas para o grupo específico, uma vez que trabalhos sobre o tema costumam utilizar os dois termos. A palavra-chave "vídeo on demand" foi utilizada para a pesquisa, tanto de forma isolada, quanto a partir da combinação com cada um dos termos dos grupos intermediário e específico.

Quadro 1: Grupos de palavras-chave

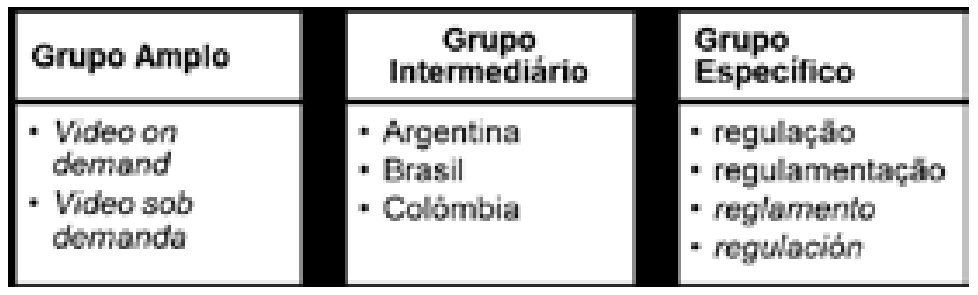

Fonte: Elaboração própria, 2020.

Feita a escolha das palavras-chave, a próxima etapa é a definição das bases de pesquisa que serão utilizadas na busca dos trabalhos. Foram selecionadas algumas bases de dados a partir da relevância acadêmica e da adequabilidade com o tema em questão. Assim, optou-se por considerar o Catálogo de Teses e Dissertações da Capes, a Biblioteca Digital Brasileira de Teses e Dissertações (BDTD), o Portal de Periódicos Capes, o Google Acadêmico e a base SSRN. A pesquisa foi realizada buscando arquivos publicados no período de 10 anos (2009-2019) e que contivessem os termos de busca no título, resumo ou nas palavras-chave das publicações. Como resultado, foram identificados 2274 trabalhos que compuseram o Banco de Materiais Brutos (BMB), base de dados que agrega todas as publicações coletadas nesta etapa da pesquisa.

Quadro 2: Quantidade de trabalhos científicos encontrados nas bases de dados

\begin{tabular}{|l|c|}
\hline \multicolumn{1}{|c|}{ Bases de Dados } & Publicações \\
\hline Catálogo de Teses e Dissertações Capes & 43 \\
\hline BDTD & 55 \\
\hline Portal de Periódicos Capes & 528 \\
\hline Google Acadêmico & 1612 \\
\hline SSRN & 36 \\
\hline TOTAL & 2274 \\
\hline
\end{tabular}

Fonte: Elaboração própria, 2020.

A etapa seguinte envolve a filtragem do Banco de Materiais Brutos para a seleção de publicações disponíveis, com aderência ao tema da pesquisa e relevantes cientificamente. $\mathrm{O}$ primeiro passo consiste na leitura de títulos 
e resumos para identificação e exclusão das publicações repetidas. Das 2274 publicações, 1072 eram redundantes e foram excluídas, restando 1202 documentos no BMB, aproximadamente $52 \%$ dos arquivos encontrados inicialmente. Na etapa seguinte, foram selecionadas publicações de diversos campos dos saberes que possuem relação mais ampla com a questão dos serviços de VOD. São textos da área de ciências exatas, como engenharias e ciências da comunicação, que se debruçam sobre aspectos técnicos e estruturais do aparato tecnológico do VOD, bem como trabalhos de comunicação social e estudos culturais, sem um olhar direto à temática da regulação. Ao fim dos dois processos, restaram 74, publicações no BMB.

Em seguida, foi realizado o reconhecimento da relevância científica a partir do número de citações das publicações. O processo foi feito a partir da pesquisa de cada arquivo no Google Acadêmico, uma vez que a plataforma possui ferramenta para o levantamento do número de citações de cada publicação. Seguindo a metodologia ProKnow-C, utilizou-se o ponto de corte de 85\%, índice sugerido para identificar as publicações relevantes. Dessa forma, foram selecionados 28 trabalhos, correspondente a $37 \%$ dos arquivos do BMB, e 46 ficaram abaixo do ponto de corte. Na próxima etapa, foi feita a leitura dos resumos, a fim de verificar a adequação dos trabalhos com o tema da pesquisa. Após esse processo, das 28 publicações que ficaram acima do ponto de corte, 14 foram excluídas, restando outras 14 .

As 46 publicações com citações abaixo do ponto de corte foram submetidas a dois processos de filtragem para determinar a permanência no BMB. Primeiramente, observou-se a data de publicação dos artigos, mantendo os trabalhos publicados de 2017 a 2019. Assim, 11 publicações foram excluídas e 35 foram mantidas. Os documentos que permaneceram foram submetidos à leitura dos resumos. Destes, 18 foram mantidos por terem aproximação com o tema.

Após as etapas dos processos de filtragem descritas anteriormente, restaram 32 documentos: 14, com citações acima do ponto de corte e 18 abaixo do ponto de corte estabelecido para o reconhecimento da relevância científica. É importante destacar que neste trabalho foram feitas adaptações da metodologia, dando preferência às publicações que possuem relação direta com o tema da pesquisa em relação ao critério do número de citações, uma vez que esse é um dentre muitos critérios para identificar a relevância de uma publicação científica, principalmente na área de comunicação e cultura.

Posteriormente, foi identificada a disponibilidade integral e gratuita dos documentos, o que resultou na exclusão de oito arquivos. Os 24, documentos restantes foram lidos integralmente e nove foram excluídos pelo baixo alinhamento com o tema da pesquisa. Os 15 documentos selecionados compõem o Portfólio Bibliográfico, grupo que serve de referência no levantamento do estado da arte da regulação do vídeo sob demanda na América do Sul. Estes se dividem em 11 artigos, 2 relatórios e 2 dissertações. 
Além dessas 15 publicações, foi incluído também o relatório "Obligations on on-demand audiovisual media services providers to financially contribute to the production of European works: an analysis of European Member States practices", desenvolvido pelo Centro de Estudos em Mídia, Inovação e Tecnologia (SMIT, na sigla original), vinculado à Universidade Livre de Bruxelas. A inclusão deste relatório foi feita pela relevância da pesquisa realizada

Por fim, cabe destacar que este texto não possui a pretensão de realizar um levantamento definitivo sobre as produções referentes à regulamentação do VOD na América do Sul. O artigo apresenta uma revisão de literatura a partir de recorte específico, conforme as escolhas metodológicas que descrevemos anteriormente, gerando, consequentemente, a possibilidade de exclusão de textos considerados relevantes para o tema em questão.

Quadro 3: Portfólio bibliográfico

\begin{tabular}{|c|c|c|c|c|c|c|}
\hline $\mathrm{N}$ & Tipo & Título & Autores & Local de Publicação & Ano & Citações \\
\hline 1 & Artigo & $\begin{array}{l}\text { Video on demand services } \\
\text { in Latin America: trends and } \\
\text { challenges towards access, } \\
\text { concentration and regulation }\end{array}$ & \begin{tabular}{|l|} 
Ezequiel \\
Rivero, Mariela \\
Baladron
\end{tabular} & $\begin{array}{l}\text { Journal of Digital Media } \\
\text { \& Policy }\end{array}$ & 2019 & 2 \\
\hline 2 & Artigo & $\begin{array}{l}\text { Redes de imbróglios: a regulação } \\
\text { do streaming no Brasil e suas } \\
\text { ambiguidades }\end{array}$ & $\begin{array}{l}\text { João Martins } \\
\text { Ladeira, } \\
\text { Leonardo de } \\
\text { Marchi }\end{array}$ & $\begin{array}{l}\text { CONTRACAMPO - } \\
\text { Brazilian Journal of } \\
\text { Communication }\end{array}$ & 2019 & 0 \\
\hline 3 & Artigo & $\begin{array}{l}\text { Analisando a CIDE- } \\
\text { CONDECINE licança a partir } \\
\text { das consequências da sua } \\
\text { incidência no segmento de } \\
\text { vídeo por deanda programado } \\
\text { (VOD-NETFLIX) }\end{array}$ & \begin{tabular}{|l} 
Vinícius \\
Alves Portela \\
Martins
\end{tabular} & $\begin{array}{l}\text { Revista de Finanças } \\
\text { Públicas, Tributação e } \\
\text { Desenvolvimento }\end{array}$ & 2018 & 0 \\
\hline 4 & Dissertação & $\begin{array}{l}\text { Propuesta regulatoria para las } \\
\text { plataformas OTT de contenidos } \\
\text { audiovisuales en Colombia }\end{array}$ & $\begin{array}{l}\text { Héctor Iván } \\
\text { Piraján } \\
\text { Aranguren }\end{array}$ & $\begin{array}{l}\text { Repositório Universidad } \\
\text { Santo Tomas }\end{array}$ & 2018 & 0 \\
\hline 5 & Relatório & $\begin{array}{l}\text { Obligations on on-demand } \\
\text { audiovisual media services } \\
\text { providers to financially } \\
\text { contribute to the production } \\
\text { of European works: an analysis } \\
\text { of European Member States } \\
\text { practices }\end{array}$ & \begin{tabular}{|l|} 
Karen Donders, \\
Tim Raats, \\
Marlen \\
Komorowski, \\
Ivana \\
Kostovska, \\
Stephanie \\
Tíntel, Catalina \\
lordache \\
\end{tabular} & $\begin{array}{l}\text { Studies in Media, } \\
\text { Innovation and } \\
\text { Technology }\end{array}$ & 2018 & 6 \\
\hline 6 & Artigo & $\begin{array}{l}\text { VOD: o bom e velho mercado de } \\
\text { vídeo doméstico }\end{array}$ & \begin{tabular}{|l} 
Gabriel Fliege \\
de Lucena \\
Stuckert
\end{tabular} & Revista Geminis & 2017 & 2 \\
\hline 7 & Artigo & $\begin{array}{l}\text { Regulação e novas tecnologias: } \\
\text { verticalização das OTTs de vídeo }\end{array}$ & \begin{tabular}{|l|} 
Carlos \\
Emmanuel \\
Joppert \\
Ragazzo, Isabel \\
Cristina Veloso \\
de Oliveira \\
\end{tabular} & $\begin{array}{l}\text { Revista da Faculdade } \\
\text { de Direito da UFRGS }\end{array}$ & 2017 & 0 \\
\hline
\end{tabular}




\begin{tabular}{|c|c|c|c|c|c|c|}
\hline 8 & Artigo & $\begin{array}{l}\text { Por que, quando e como regular } \\
\text { as novas tecnologias? Os } \\
\text { desafios trazidos pelas inovações } \\
\text { disruptivas }\end{array}$ & $\begin{array}{l}\text { Clara Iglesias } \\
\text { Keller, Patrícia } \\
\text { Baptista }\end{array}$ & \begin{tabular}{|l} 
RDA - Revista de \\
Direito Administrativo
\end{tabular} & 2016 & 11 \\
\hline 9 & Artigo & $\begin{array}{l}\text { Vídeo sob demanda: uma nova } \\
\text { plataforma televisiva }\end{array}$ & \begin{tabular}{|l} 
Dario \\
Mesquita, \\
João Carlos \\
Massarolo \\
\end{tabular} & $\begin{array}{l}\text { Anais - XXV Encontro } \\
\text { Anual da Compós }\end{array}$ & 2016 & 10 \\
\hline 10 & Dissertação & $\begin{array}{l}\text { A Lei da TV Paga: impactos no } \\
\text { mercado audiovisual }\end{array}$ & $\begin{array}{l}\text { Heverton } \\
\text { Souza Lima }\end{array}$ & Biblioteca Digital USP & 2015 & 13 \\
\hline 11 & Artigo & $\begin{array}{l}\text { The Television Struggle: An } \\
\text { Assessment of Over-the-Top } \\
\text { Television Evolutions in a Cable } \\
\text { Dominant Market }\end{array}$ & \begin{tabular}{|l} 
Bastian \\
Baccarne, \\
Dimitri \\
Schurmann, \\
Tom Evens \\
\end{tabular} & $\begin{array}{l}\text { Communications \& } \\
\text { Strategies Journal }\end{array}$ & 2014 & 36 \\
\hline 12 & Artigo & $\begin{array}{l}\text { Problemas na Definição Legal } \\
\text { Brasileira de TV Sob Demanda } \\
\text { Via Internet. }\end{array}$ & \begin{tabular}{|l|} 
Dalila Alves \\
Corrêa, Glauco \\
Madeira de \\
Toledo, Willian \\
Machado de \\
Andrade \\
\end{tabular} & Revista Geminis & 2013 & 3 \\
\hline 13 & Artigo & Supervising Managed Services & James B. Speta & Duke Law Journal & 2011 & 13 \\
\hline 14 & Relatório & $\begin{array}{l}\text { Un modelo institucional para } \\
\text { la regulación en materia de } \\
\text { convergencia tecnológica en } \\
\text { América Latina }\end{array}$ & René Bustillo & $\begin{array}{l}\text { CEPAL - Colección } \\
\text { Documentos de } \\
\text { Proyectos }\end{array}$ & 2011 & 8 \\
\hline 15 & Artigo & $\begin{array}{l}\text { Co-Regulation, Video-on- } \\
\text { Demand and the Legal Status of } \\
\text { Audio-Visual Media }\end{array}$ & Daithi Sithigh & $\begin{array}{l}\text { International Journal of } \\
\text { Digital Television }\end{array}$ & 2011 & 7 \\
\hline 16 & Relatório & $\begin{array}{l}\text { Perspectivas de las tecnologías } \\
\text { de telecomunicaciones y sus } \\
\text { implicancias en los mercados y } \\
\text { marcos regulatorios en los países } \\
\text { de América Latina y el Caribe }\end{array}$ & Omar de León & $\begin{array}{l}\text { CEPAL - Colección } \\
\text { Documentos de } \\
\text { Proyectos }\end{array}$ & 2009 & 14 \\
\hline
\end{tabular}

Fonte: Elaboração própria, 2020.

\section{Discussão e resultados}

O primeiro ponto a ser destacado refere-se ao intervalo temporal. Sete trabalhos foram publicados entre 2017-2019, demonstrando o crescimento da produção acadêmica sobre a regulação do VOD nos últimos anos. No recorte temporal, se ressalta que 2011 concentra três dos 16 trabalhos analisados, período que coincide com o início da popularização dos serviços de VOD na América Latina.

A maior parte dos trabalhos foram publicados na área de Comunicação (9), seguida por Direito (3). Destacam-se a Revista Geminis, periódico vinculado ao Programa de Pós Graduação em Imagem e Som da Universidade Federal de São Carlos, e a Coleção de Documentos de Projetos da Comissão Econômica para a América Latina e o Caribe (CEPAL). 
A partir da análise dos textos, foram identificados e sistematizados quatro pontos principais que identificam o estado da arte da produção acadêmica sobre a regulação dos serviços de vídeo sob demanda na Argentina, no Brasil e na Colômbia: a) regulação para novas tecnologias; b) entraves e potencialidades das regulamentações; c) diferenças entre a construção regulatória na Europa e na América Latina; e d) relação entre a regulamentação para o VOD e mercado e normativas para a TV Paga.

\subsection{Regulação para novas tecnologias}

A revisão de literatura identificou que a regulação para a comunicação audiovisual sob demanda está inserida em uma agenda mais ampla, referente à regulação para as novas tecnologias. Além de destacar o papel do Estado, os autores também ressaltam que os atores e relações estabelecidas no contexto internacional são centrais no processo de elaboração dos marcos regulatórios.

Para além da regulação dos serviços de VOD, os textos de Speta (2011), Baptista e Keller (2016); Sithigh (2011) e Baladrón e Rivero (2019) abordam a regulação das novas tecnologias de um modo geral. Os autores ressaltam a rápida evolução das transformações nas quais esses serviços e tecnologias estão inseridos e a tendência de se elaborar regulamentações baseadas em experiências anteriores. Os dois cenários são apontados como caminhos problemáticos que podem levar ao travamento de processos e a instrumentos regulatórios ineficazes.

Baptista \& Keller (2016) propõem uma tipologia das relações entre Estado e sociedade civil que surgem a partir da criação e operacionalização de um instrumento regulatório para novas tecnologias. As relações são classificadas de acordo com a) equivalência; b) instrumentalidade; c) incentivo; e d) normatização. O trabalho ressalta as formas nas quais o Estado pode se relacionar com o surgimento de novas tecnologias através da regulamentação, atuando, por exemplo, como estimulador da inovação tecnológica e regulador das dinâmicas de mercado. Ao direcionarem seus olhares para a eficiência da regulamentação destes novos serviços, as autoras se baseiam em conceitos como "inovação disruptiva"2 e "desconexão regulatória"3. O estudo oferece subsídios para debater as formas nas quais o VOD se aproxima ou distancia de outros serviços que possuem o ambiente digital como lócus de operação.

No que concerne ao papel de organizador das dinâmicas de mercado, o Estado atua no combate às práticas de monopólio desempenhadas por grandes corporações internacionais. A relação entre estes atores do sistemainternacional

2 Baptista e Keller incorporam a definição de Nathan Cortez em "Regulating disruptive innovations": "Uma inovação disruptiva ocorre quando for capaz de enfraquecer ou, eventualmente, de substituir indústrias, empresas ou produtos estabelecidos no mercado". (CORTEZ, 2014 apud BATISTA \& KELLER, 2016, p. 130)

3 "Desconexão regulatória" é incorporado no texto das autoras a partir da aplicação do termo por Brownsword e Goodwin (2012) referindo-se a "quando, de tempos em tempos, surge a necessidade de reconexão entre o arcabouço regulatório e o panorama geral de mercado". (BATISTA \& KELLER, 2016, p. 139) 
no processo de incorporação de inovações tecnológicas são cruciais para o desenvolvimento de normativas e políticas nacionais. É nesse sentido que James Speta (2011) chama a atenção para o cuidado necessário no alinhamento entre os objetivos dos marcos regulatórios e as tendências mercadológicas, sobretudo para que tais instrumentos atuem como promotores e não como freios para a inovação.

Os serviços over the top reverberam em suas discussões regulatórias não apenas especificidades do setor de telecomunicações e audiovisual, mas também do setor de tecnologia como um todo. A alta velocidade de mudança que as inovações tecnológicas impõem às estruturas sociais e econômicas de todos os países do globo, pede um alinhamento entre as mais diversas esferas que compõem a sociedade para a elaboração dos marcos regulatórios.

\subsection{Entraves e potencialidades da regulamentação do vídeo sob demanda}

Um olhar atento acerca da construção de regulamentação para novas tecnologias e plataformas de áreas diversas é potente elemento para o aprofundamento da discussão regulatória específica para os serviços OTTs nos países da América Latina. Apesar das distinções nas estruturas social, econômica e política, os países latino americanos compartilham um histórico de colonização e exploração que os relegou à condição de países periféricos do sistema internacional e influenciou diretamente no atraso do processo desenvolvimentista.

Nesse sentido, o segundo ponto de abordagem são as potencialidades e entraves que a regulamentação para o vídeo sob demanda traria aos países e consumidores da região. Este é um argumento transversal a quase todas as publicações analisadas. São argumentos que dialogam com pautas sobre diversidade cultural, desenvolvimento de tecnologias e serviços, acesso a cultura e fortalecimento e manutenção de novos e velhos modelos de negócios.

Grande parte dos argumentos colocados por grupos favoráveis à regulamentação do VOD compartilham a narrativa da necessidade de normativa para esses serviços como garantia da execução de obrigações estabelecidas em instrumentos regulatórios anteriores do audiovisual. A exemplo pode-se citar contribuições para fundos de financiamento à produção nacional - como o Condecine, no Brasil, e o cumprimento da cota de telas para a exibição de produções nacionais. Tais encargos já são exigidos de serviços como TVs por assinatura, mas ainda não estão definidos no caso do VOD.

O estabelecimento de regulamentação para estes novos serviços é visto por autores como Massarolo \& Mesquita (2016) e Martins (2018) como importantes para a consolidação de instrumentos de fomento à cultura nacional e controle do monopólio de indústrias estrangeiras do setor audiovisual. No epicentro da questão está a discussão sobre eficiência e eficácia da atualização das normativas já existentes ou a criação de novas que tenham como objeto os serviços OTTs. 
Baladrón \& Rivero (2019) destacam o contexto neoliberal no qual grande parte dos países latino americanos estavam inseridos durante a emergência das tecnologias digitais. Para os autores, essa relação resultou em uma ideia de conexão automática entre tecnologias digitais e diversidade cultural. Ideia essa que posteriormente não se provou verdadeira, principalmente a partir de análises sobre o importante papel do Estado como regulador de questões sociais como pluralismo, diversidade, interconexão e acesso (IOSIFIDIS, 2016 \& BALADRÓN \& RIVERO, 2019, p. 112).

Todavia, a atuação estatal na regulamentação enfrenta resistência baseada na justificativa de prejuízo à inovação tecnológica. Destaca-se na revisão de literatura que o recolhimento de impostos e taxas são indicados por grandes empresas como inibidores de novos investimentos nacionais e estrangeiros, reduzindo as oportunidades de inovação no setor.

O diálogo entre as instâncias do Estado, responsáveis pela construção regulatória, e do mercado, responsáveis pela operação destas novas tecnologias, é essencial para uma regulamentação que supere os entraves colocados pelos autores. Essa aproximação se faz ainda mais necessária no cenário de rápida evolução das tecnologias e de seus modos de operação. $\mathrm{O}$ afastamento entre as duas instâncias pode resultar em entraves burocráticos e operacionais, responsáveis por instrumentos ineficazes e que não cumprem seus objetivos sociais. De modo mais grave, pode ainda contribuir para o agravamento na defasagem de países periféricos na incorporação de novas tecnologias digitais, sobretudo para as telecomunicações.

A alta probabilidade de que uma regulamentação seja criada com defasagem em sua operacionalização ressalta a importância de que a estrutura regulatória para o audiovisual esteja centrada em conteúdo e consumo, e não necessariamente na estrutura tecnológica, como é percebido no caso brasileiro. Esse argumento é trabalhado por Andrade et al (2013), baseado nas reflexões de Eli Noam (2008) a partir do contexto canadense, no qual

percebe-se que a tentativa de definição canadense das novas tecnologias audiovisuais em contexto regulatório aborda a TV não a partir, exclusivamente, de seus métodos e técnicas de transmissão (a cabo ou satélite), mas também por suas características de utilização pelo público. (Andrade et al, 2013, p. 118)

Pensar a regulamentação a partir destes termos não quer dizer, contudo, que a estrutura tecnológica não seja importante para a elaboração de marcos regulatórios. Entretanto, um foco a partir do conteúdo distribuído e suas formas de consumo pode resultar em regulamentações mais duradouras, sem necessidade de revisão a cada atualização tecnológica. 


\subsection{Diferenças entre a construção regulatória na Europa e na América Latina}

A elaboração de instrumentos regulatórios para os serviços OTTs é uma ação que vem sendo desempenhada em diversas partes do globo, com diferentes níveis de amadurecimento e abordagens. Alguns trabalhos do Portfólio Bibliográfico investigam os processos de regulamentação em desenvolvimento na Europa e as mudanças trazidas pelo VOD para o mercado audiovisual. O paralelo entre os contextos sul-americano e europeu é importante, pois identificar as experiências de diferentes regiões pode resultar em um potente material para o aprofundamento das discussões regulatórias.

Os trabalhos de León (2009) e Bustillo (2011), desenvolvidos no âmbito da CEPAL, e financiados com recursos da União Europeia, são investigações que temporalmente convergem com a explosão e a popularização dos serviços de vídeo sob demanda e o consequente início dos debates sobre regulamentação. A ligação entre estes estudos e o financiamento europeu pode indicar o estímulo a pesquisas nesta área, focadas na América Latina, para a construção de conhecimento científico sobre um processo ainda incipiente naquele momento.

O relatório da pesquisa desenvolvida pelo SMIT (Donders et al, 2018) é importante de ser destacado aqui. Ainda que o foco do trabalho dos pesquisadores da universidade belga se direcione para a experiência de regulamentação dos países da União Europeia, destaca-se as experiências de Argentina, Brasil e Colômbia como países sul-americanos que estão construindo instrumentos regulatórios para o audiovisual.

Como exemplo de características que se destacam na experiência da Europa pode-se sinalizar a inegável importância de instituições supranacionais do bloco europeu, como o Observatório Europeu do Audiovisual e o Diretório Geral para Comunicações, para o estabelecimento de pautas referentes às telecomunicações e ao audiovisual na agenda regional e nacional dos países membros. A convergência da discussão no contexto interno e supranacional da União Europeia para a construção de normativas são pontos diferenciais quando comparados com os países da América do Sul, que não possuem órgãos supranacionais do audiovisual altamente institucionalizados (Canedo, 2013). Nesse sentido, Sithigh (2011) realça que a co-regulação entre países a partir do ambiente supranacional é um fator de fortalecimento do debate se trabalhado a partir do diálogo com normas nacionais e a auto-regulação do próprio setor. Assim como a construção da regulamentação para o VOD na UE pode estar relacionada à existência desses órgãos, a ausência e fragilidade na América Latina pode explicar a aparente inconstância do processo.

Tanto na Europa, quanto na América Latina, o surgimento dos serviços de vídeo sob demanda trouxe novos paradigmas para o consumo de vídeo doméstico e suscitou debates sobre sua relação com as formas tradicionais de exibição, sobretudo a TV por assinatura. Nesse sentido, uma regulamentação para estes distintos modelos deveria levar em consideração que, como afirma 
Baccarne, Evens e Schuurman (2014), não se tratam de serviços diametralmente opostos, mas sim complementares.

\subsection{Relação entre VOD e TV por assinatura}

A íntima relação entre o vídeo sob demanda e a TV por assinatura para o tema da regulamentação é evidenciada na revisão de literatura a partir de diversas perspectivas, com destaque para duas principais abordagens.

A primeira analisa a regulamentação como ferramenta necessária para a organização da competição entre os serviços de VOD e da TV por assinatura. A emergência dos novos serviços para o audiovisual é constantemente atrelada à redução dos usuários da TV por assinatura, apontada como possível causa da crise deste setor. Todavia, esse é um debate aberto, uma vez que os especialistas se dividem entre os que acreditam em um impacto direto e contundente do VOD para o setor da TV tradicional, enquanto outros defendem um efeito limitado do fenômeno do VOD sobre a aparente crise que atinge a televisão por assinatura nos últimos anos (Banejee et al, 2012 \& Baccarne et al, 2014).

Baccarne et al (2014) argumenta que o preço da assinatura se coloca como fator determinante para a escolha do serviço contratado, mas não é o único elemento levado em consideração pelos usuários. A necessidade de conexão à internet e até mesmo a tela em que o consumo será feito são elementos que influenciam diretamente na escolha entre VOD e TV por assinatura. Nesse sentido, a depender da faixa de renda, a escolha pelo VOD não necessariamente funciona como substituto ao modelo de exibição linear das televisões, mas sim como complementar.

A questão financeira é o segundo argumento de destaque, uma vez que é um dos pontos centrais das considerações das empresas de TV por assinatura sobre a regulamentação. Constantemente, tais empresas afirmam que as obrigações, sobretudo tributárias, presentes nos instrumentos regulatórios, reverberam no valor repassado aos usuários e constrangem novos investimentos para a área. Por outro lado, a falta de normativas claras para os serviços OTTs, abrindo possibilidade de manobras para fugir da regulamentação, facilitaria a oferta de serviços a um menor preço e, consequentemente, em uma concorrência desleal. A construção de regulamentação para os serviços de vídeo sob demanda ou até mesmo a flexibilização das obrigações impostas à TV por assinatura é comumente indicada como a resolução para este imbróglio.

Como percebido nos textos de Martins (2018), Ladeira \& Marchi (2019), Lima (2015) e Aranguren (2018), as obrigações tributárias se apresentam como o grande "calcanhar de Aquiles" da regulamentação. Alguns autores defendem que o problema não está na tributação em si, mas na forma como os instrumentos vêm sendo administrados e empenhados. Uma possível revisão dos instrumentos não significaria necessariamente o enfraquecimento das obrigações para o setor, mas poderia refletir no aumento da eficiência e na 
consecução dos objetivos pretendidos. Segundo Aranguren (2018, p. 145), no caso colombiano, existe uma base sólida em normativas anteriores do setor audiovisual, capaz de auxiliar a revisão de normativas para a TV por assinatura e a criação de uma nova normativa que regule os serviços de VOD, priorizando o usuário final, e coerente com as recomendações de órgãos internacionais especializados.

\section{Conclusão}

O ambiente digital tem se tornado central para a área cultural, incidindo diretamente nas dinâmicas dos diferentes elos da cadeia produtiva do setor, passando pela produção, distribuição e consumo. Segundo dados do Sistema de Informações e Indicadores Culturais (SIIC) 2007-2018, do Instituto Brasileiro de Geografia e Estatísticas (IBGE), 59,9\% dos gastos das famílias brasileiras com cultura acontece no ambiente digital, através do grupo "Serviço por telefonia, TV por assinatura e internet” (IBGE, 2019).

O consumo de conteúdo audiovisual é elemento representativo da importância do ambiente digital para a cultura, tornando- se ainda mais evidente no contexto da pandemia do coronavírus. No epicentro do fenômeno estão os serviços de vídeo sob demanda com todas as inovações e novos paradigmas que surgiram nesta toada. Ainda assim, como defendido por Stuckert (2017, p. 12), o VOD pode ser entendido como uma "nova forma de prestar um velho serviço que faz parte de um ‘antigo' segmento: o mercado de vídeo doméstico”. Neste sentido, sua relação com a TV por assinatura não se dá somente através da concorrência, mas também pela complementaridade, sendo uma forma de exibição e consumo que se soma às formas tradicionais da cadeia do audiovisual. Não se trata então de uma substituição, mas sim de transformações para o setor.

A questão da regulamentação direcionada ao VOD é um debate transversal que envolve os diferentes pontos abordados durante este texto: refere-se ao processo de inovação tecnológica, abarcando outras áreas para além do audiovisual; traz à tona a discussão sobre as obrigações regulatórias para os serviços tradicionais do setor; assim como também supera limites geográficos uma vez que, apesar das especificidades de cada país e região, é um fenômeno identificado em várias partes do globo. Olhar para essas diferentes experiências é se valer de uma visão panorâmica que pode auxiliar a superação de entraves a partir da identificação de boas práticas e equívocos a serem evitados.

Através de uma revisão de literatura, o artigo destacou o estado da arte sobre a regulação para o vídeo sob demanda a fim de identificar tópicos consonantes entre os trabalhos que compuseram o Portfólio Bibliográfico e que possam auxiliar o entendimento sobre este tema que tem ganhado cada vez mais relevância não só para o audiovisual, mas para o setor cultural como um todo. 


\section{Referências}

Ancine. Audiovisual brasileiro gerou $\mathrm{R} \$ 26,7$ bilhões à economia do país. 2020. Disponível em: https:/www.gov.br/ancine/pt-br/assuntos/noticias/audiovisual-brasileiro-gerou-r-26-7-bilhoes-a-economia-do-pais. Acesso em: 28 fev. 2021.

Andrade, Wiliam M; Toledo, Gabriel m.; Corrêa, Dalila.A. Problemas na Definição Legal Brasileira de TV Sob Demanda Via Internet. Revista Geminis, São Carlos, v. 4, n. 1, p.108126, jan/jun. 2013.

Aranguren, Héctor I. P. Propuesta regulatoria para las plataformas de contenidos audiovisuales en Colombia. In: Repositório Universidad Santo Tomas. Disponível em: https:// repository.usta.edu.co/handle/11634/15374. Acesso em: 18 dez. 2019.

Baccarne, Bastian; Evens, Tom; Schuurman, Dimitri. The television struggle: An assessment of over-the-top television evolutions in a cable dominant marke. In: Communications $\mathcal{E}$ Strategies, n. 92, pp. 43-61, 2013. Disponível em: https://papers.ssrn.com/soL3/papers. cfm?abstract_id=2473955. Acesso em: 03 jan. 2020.

Baladron, Mariela; Rivero, Ezequiel. Video on deman services in Latin America: Trend and challenges towards access, concentration and regulation. In: Journal of Digital Media \& Policy, v. 10, n. 1, pp. 109-126, 2019.

Baptista, p.; Keller, Clara I. Por que, quando e como regular as novas tecnologias? Os desafios trazidos pelas inovações disruptivas. In: RDA - Revista de Direito Administrativo, Rio de Janeiro, v. 273, p. 123-163, set./dez. 2016

Bolaño, César; Manso, Anna Carolina. Para uma economia política do audiovisual brasileiro. Cinema, televisão e o novo modelo de regulação da produção cultural. In: MELEIRO, Alessandra (org). Cinema e Economia da Cultura. Indústria Cinematográfica e Audiovisual Brasileira. Vol. II. São Paulo: Escrituras, 2009.

Brownsword, Roger; Goodwin, Morag. Law and the Technologies of the Twenty-first Century: Text and Materials. Cambridge University Press, 2012.

Bustillo, René. Un modelo institucional para lá regulación en materia de connvergencia tecnológica en América Latina. In: Colección Documentos de Proyectos - CEPAL, Santiago, Chile, 2011. Disponível em: https://repositorio.cepal.org/handle/11362/3916. Acesso em: 11 nov. 2019.

Canedo, D. P. Todos contra Hollywood? Políticas, Redes e Fluxos do Espaço Cinematográfico do Mercosul e a Cooperação com a União Europeia. Universidade Federal da Bahia. Faculdade de Comunicação. Tese de Doutorado (Pós-Cultura). Salvador-BA, 2013.

CISCO. Cisco prevê mais tráfego IP nos próximos cinco anos do que em toda a história da Internet. Cisco, 2018. Disponível em: https://www.cisco.com/c/pt_pt/about/press/ news-archive-2018/20181127.html. Acesso em: 18 dez. 2019.

Cortez, Nathan. Regulating disruptive innovation. Berkeley Technology Law Journal, Berkeley, n. 29, p. 175-228, 2014.

Donders, Karen. et al. Obligations on on-demand audiovisual media services providers to financially contribute to the production of European works: An analysis of European member states' practices. Brussels: Vrije Universiteit Brussel, 2018.

Ensslin, Leonardo, Ensslin, S. R., Lacerda, \& Tasca, 2010. ProKnow-C, Knowledge Development Process- Constructivist. Processo técnico com patente de registro pendente junto ao INPI. Brasil.

Furtado, Celso. Desenvolvimento e subdesenvolvimento. Rio de Janeiro: Fundo de Cultura, 1961. 
GARNHAM, Nicholas. Contribution to a political economy of mass media. In: GARNHAM, Nicholas (Ed.). Capitalism and communication. Londres: Sage, 1979.

Golding, Peter; Murdock, Graham (Org.) The Political Economy of the Media. 2 v. Leicestershire: Edgar Elgar Publisher, 1981.

Ladeira, João M.; Marchi, Leonardo. Redes de Imbróglios: a regulação do streaming no Brasil e suas ambiguidades. In: Contracampo, Niterói, v. 38, n.3, p. 68-79. 2019.

León, Omar de. Perspectivas de las tecnologías de telecomunicaciones y sus implicancias en los mercados y marcos regulatorios en los países de América Latina y el Caribe. In: Colección Documentos de Proyectos - CEPAL. Santiago, Chile, 2009. Disponível em: https:// repositorio.cepal.org/handle/11362/3728. Acesso em 11 nov. 2019.

Lima, Heverton S. A lei da tv paga: impactos no mercado audiovisual. 2015, 162f. Dissertação de Mestrado - Universidade de São Paulo, São Paulo, 2015. In: Biblioteca Digital USP. Disponível em: https://teses.usp.br/teses/disponiveis/27/27161/tde-26062015-162615/ en.php. Acesso em: 15 nov. 2019.

Martins, Vinícius A. P. Analisando a CIDE-CONDECINE licença a partir das consequências da sua incidência no segmento de vídeo por demanda programado (VOD - NETFLIX). In: Revista de Finanças Públicas, Tributação e Desenvolvimento, Rio de Janeiro, v. 6, n. 6, 2018.

Massarolo, João C.; Mesquita, Dario. Vídeo sob Demanda: uma nova plataforma televisiva. In: XXV ENCONTRO ANUAL DA COMPOS, 25, 2016, Goiânia. Estudos da Televisão. Goiânia: 2016. p. 1 - 24.

Morais, Kátia; Jambeiro, Othon; Ferreira, Fábio. O audiovisual no campo da economia política da comunicação: abordagens, métodos e notas para uma agenda de pesquisa. Revista Extraprensa, v. 10, n. 2, p. 04-23, 2017. Disponível em: https://www.revistas.usp.br/ extraprensa/article/view/121975/130487. Acesso em: 06 ago. 2021.

Mosco, Vicent. The Political Economy of Communication. Rethinking and Renewal. Londres: Sage Publications, 1996, $307 \mathrm{p}$.

Noam, Eli. TV or Not TV: Three Screens, One Regulation? In Canadian Radio-television and Telecommunications Commission. Disponível em: <http://www.crtc.gc.ca/eng/media/ noam2008.htm\#toc4>. Acesso em: 15 abr 2020.

ragazzo, carlos e.j.; oliveira, isabel C. V. de. Regulação e novas tecnologias: o caso das OTTs de vídeo. In: Revista da Faculdade de Direito da UFRGS, Porto Alegre, n. 37, p. 200-2018, 2017.

Sen, Amartya. Desenvolvimento como liberdade. Tradução Laura Teixeira Motta. São

Paulo: Companhia das Letras, 2000.

Sithigh, Daithi M. Co-regulation, video on demand and the legal status of audio visual media. In: International Journal of Digital Television, vol. 2, n. 1, pp. 51-68, 2011. Disponível em: https://papers.ssrn.com/sol3/papers.cfm?abstract_id=1728664. Acesso em 03jan. 2020.

Speta, James B. Supervising managed services. In: Duke Law Journal, vol. 6o, n. 8, 2011. Disponível em: https://papers.ssrn.com/sol3/papers.cfm?abstract_id=1837669\#\#. Aceso em: 03 jan. 2020.

Stuckert, Gabriel F. de L. VOD: o bom e velho mercado de vídeo doméstico. Revista Geminis, São Carlos, v. 8, n. 2, p. 04-15, 29 ago. 2017.

UNESCO. Convenção sobre a proteção e a promoção da diversidade das expressões culturais. 2006. Disponível em: http://unesdoc.unesco.org/images/o015/o01502/150224POR.pdf>. Acesso em: 15 de out.

2019 . 